\title{
A DATA DRIVEN DECISION MAKING APPROACH FOR LONG-WALL MINING PRODUCTION ENHANCEMENT
}

\author{
A. MORSHEDLOU ${ }^{1}$, H. DEHGHANI ${ }^{1}$, \\ S.H. HOSEINIE ${ }^{2}$ \\ ${ }^{1}$ Department of Mining Engineering, Hamedan University of Technology, Hamedan, Iran \\ 2 Department of Mining Engineering, Isfahan University of Technology, Isfahan, Iran
}

\begin{abstract}
Machine failures have destructive effects on continuity of operation and lead to production losses in long-wall mines, making proper maintenance scheduling essential. This paper models the reliability of the whole production chain in an Iranian long-wall mine including the drum shearer, Armored Face Conveyor (AFC), hydraulic powered supports, Beam Stage Loader (BSL), and main conveyer belt. Analyzing the computational results and failure frequencies, we rank the critical components and develop a reliability-based preventive maintenance schedule for all equipment. In respect to the data classification, conveyor belt with failure abundance of 41.5 percent is the most critical, while powered supports with the failure abundance of 1.2 percent shows the best performance. Approximately, the reliability of the production process after four hours reaches nearly to zero. Implementing the schedule, computational results suggest an increase of approximately 67.7 percent in the average production per shift.
\end{abstract}

Keywords: Longwall system, reliability, maintenance, production risk

\section{INTRODUCTION}

Advanced mechanization and modernization of equipment has played a significant role in increasing the production rate in long-wall mines over the past four decades. Most of the world's coal is mined using a fully-mechanized long-wall mining method; with a new generation of automated long-wall system is coming into effect. Long-wall mining is a well-known mining method featuring the continuous operation of a chain

\footnotetext{
* Corresponding author: dehghani@hut.ac.ir (H. Dehghani)
}

doi: $10.37190 / \mathrm{msc} 192601$ 
of equipment: drum shearer, armored face conveyor (AFC), hydraulic powered supports, beam stage loader (BSL) and main conveyer belt. To meet production goals, all equipment must work properly. Therefore, we have to consider all components which are involved in the process to improve long-wall production. Production improvement generally requires (Henkel; 1991):

1 - Machines and equipment adapted to the prevailing condition of the deposit;

2 - Long operation time per day;

3 - High machine running time / high availability;

4 - Optimization of the individual performance factors within the overall system.

All production improvement strategies on this list, except the first one, are related to machine operation, with a focus on achieving maximum working hours. Reliability is a key factor and could be a suitable measure to analyze and model machine performance and production stoppages. Higher reliability of machines means more continuous and reliable production process. The other key factor which affects daily output is the integrated effectiveness of the long-wall face subsystems (Shen and Jiang; 1991).

Optimal maintenance planning is a direct way to improve the reliability and effectiveness of production equipment. To support the production plan, a long term maintenance development strategy to establish the level of asset utilization required to deliver the expected performance. This enables the preparation of detailed work programs; with effective scheduling, a mining operation can increase labor utilization and facilitate more effective materials management (Shen and Jiang 1991). Improving maintenance performance requires (Clark et al. 1991):

1 - Driving up the productivity of assets;

2 - Reducing the maintenance cost per unit of output.

Since the late 1908s, a great deal of research has proposed mathematical and quantitative analysis methods to improve the reliability and maintenance of mining equipment (Hoseinie 2011). Initial studies took qualitative approaches and largely consist of descriptions of machine failures and production delays. Although, reliability engineering has been applied to the mining industry widely since 1960, with new developments in mining equipment, reliability analysis has become more complicated.

Considering the harsh working conditions and continuous operation of long-wall mines, it is crucial to analyze the reliability and maintenance of mining equipment. However, compared to other mining methods or equipment these concepts are sparse in the literature review. Table 1 presents a short list of important analyses of reliability, maintenance and production in long-wall mines.

The literature review indicates that the production risk and the effects of a maintenance plan on production improvement have not yet been studied. This paper combines production improvement and risk scenarios considering equipment reliability and maintenance planning. We begin by modeling the reliability of each component in the long-wall mine production system, and then we analyze the production reliability. 
Based on the reliability thresholds, we design a preventive maintenance plan. Finally, it analyzes the effects of various production scenarios on the mine output.

Table 1. Research into longwall reliability and production

\begin{tabular}{|l|l|}
\hline Subject of study & Author \\
\hline Longwall utilization and production & Fawcett \& Duncan (1988) \\
\hline Longwall productivity & Velzeboer (1988) \\
\hline Reliability of longwall machines and systems & Cutts (1991) \\
\hline Production improvement techniques & Henkel (1991) \\
\hline Production reliability & Shen \& Jiang (1991) \\
\hline Reliability and availability of coal mining machines & Mrig (1991) \\
\hline Longwall equipment & Mandal \& Banik (1996) \\
\hline Reliability issues in longwall mining & CMTE (2002) \\
\hline Maintenance planning for drum shearer & Gupta et al. (2006) \\
\hline Reliability analysis of conveyor belt & Gupta \& Bhattacharya (2007) \\
\hline Production system reliability & Bing-yuan et al. (2009) \\
\hline Reliability and maintenance planning for drum shearer & Hoseinie et al. (2012) \\
\hline Powered supports reliability & Morshedlou et al. (2014a) \\
\hline Availability of main conveyor & Furuly et al. (2014) \\
\hline Risk based maintenance strategy & Gharahasanlou et al. (2015) \\
\hline
\end{tabular}

\section{RELIABILITY OF REPAIRABLE SYSTEMS}

Quantitative reliability analysis techniques use real failure data (obtained from a test program or from field operations) in conjunction with suitable mathematical models to estimate product or system reliability. Three stochastic processes are generally used for reliability analysis of repairable systems (Hoseinie et al. 2013):

1 - Renewal process (RP);

2 - Homogeneous Poisson process (HPP);

3 - Non-homogeneous Poisson process (NHPP).

A renewal process is a counting process where the inter-occurrence times are independent and identically distributed with an arbitrary life distribution (Rausand and Høyland 2004). Upon failure, the component is replaced or restored to as good as new condition. The non-homogenous Poisson process (NHPP) is often used to model repairable systems subject to minimal repair. Typically, the number of discrete events may increase or decrease over time because of the trends in the observed data. An essential condition of any homogeneous Poisson process (HPP) is that the probability of events occurring in any period is independent of what has occurred in the preceding periods. Therefore, an HPP describes a sequence of independent and identically distributed (iid) exponential random variables. Conversely, an NHPP describes a sequence of 
random variables that are neither independent nor identically distributed. The NHPP differs from the HPP in that the rate of occurrence of failure varies with time rather than remaining constant. The renewal process and the NHPP are generalizations of the HPP, both having the HPP as a special case.

To determine whether a process is HPP or NHPP, we must perform trend analysis and a serial correlation test to discover whether an iid situation exists (Kumar and Klefsjo 1992). The first step is a trend analysis. If the assumption that stands for identically distributed data is not valid, we must fit a non-stationary model such as nonhomogeneous Poisson process (NHPP). The second step is to perform a correlation test on the data. If there is no trend and no serial correlation in failure data, the data is iid, and the renewal process is the best method to model reliability.

The trend test can be done either analytically or graphically (Kumar, 1990). There are five analytical methods the testing for trends: reverse arrangement test, military handbook test, Laplace test, likelihood-ratio test, and area test. The military handbook test is a better method to find significance when the choice is between no trend and an NHPP power law model. This test checks the trend presence by calculating the test statistic $U$ (Eq. (1)) (MIL-STD-2173 1986):

$$
U=2 \sum_{i=1}^{n} \operatorname{Ln}\left(\frac{T_{n}}{T_{i}}\right),
$$

where $n$ is the total number of failures, $T_{n}$ is the time of the nth failure and $T_{i}$ is the time of the $i$-th failure. Under the null hypothesis of an HPP, the test statistic $U$ is chisquared, distributed with $2(n-1)$ degrees of freedom. If the null hypothesis is rejected at the five percent level of significance, this means the time between failures (TBFs) data have a trend and, therefore, are not identically distributed (Kumar 1990).

A test was performed in order to determine serial correlation by plotting the $i$-th TBF against the $(i-1)$-th TBF, $i=1,2, \ldots, n$. If the plotted points are randomly scattered without any pattern, we interpret this as a general lack of correlation among the TBF data; in other words, the data are independent. The Kolmogorov-Smirnov $(K-S)$ test is classically used to validate and select the best-fit distribution when the number of data is low (Kumar and Klefsjo 1992).

\section{CASE STUDY: AN IRANIAN LONGWALL MINE}

The case study is Tabas coal mine from the center desert of IRAN. This mine started to work ten years ago, and the third panel is now nearly completed. According to the production plan, the production rate should be 1.5 million tons per year at this time. However, because of equipment failures and system breakdowns, the mine has serious problems, with the extraction process often facing long downtimes. The production 
rate is about 500000 tons per year. In some shifts, equipment has failed more than ten times, causing production to stop for about five hours. The useful time of the production process is extremely low.

To perform a production reliability analysis, a series configuration of machineries was considered in the reliability block diagram as shown in Figure 1.

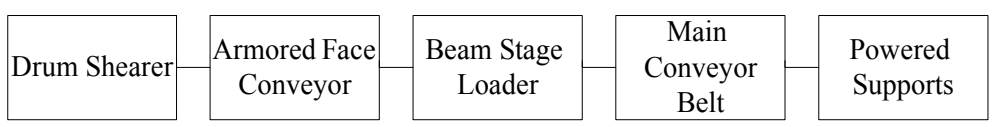

Fig. 1. Reliability block diagram of long-wall production process

We use the failure data for one whole panel to perform reliability analysis of each subsystem. The length of the studied long-wall face is $215 \mathrm{~m}$, and a panel length is $1200 \mathrm{~m}$. Since this mine operates under ISO 14000 standards, all detailed operation and maintenance data were available. To build up the main analysis database, data from the various databases was obtained and combined. We extract the data for the studied panel during 960 working shifts and 2606 hours of cutting operation. Each shift lasts seven hours, and we added one hour for shift changes and employee transfer, making a total of eight hours.

\subsection{DATA ANALYSIS}

The first stage involved Pareto analysis (failure frequency analysis) of the available data to identify critical subsystems in the coal cutting and production chain which is illustrated in Fig. 2 (Barabady and Kumar 2007).

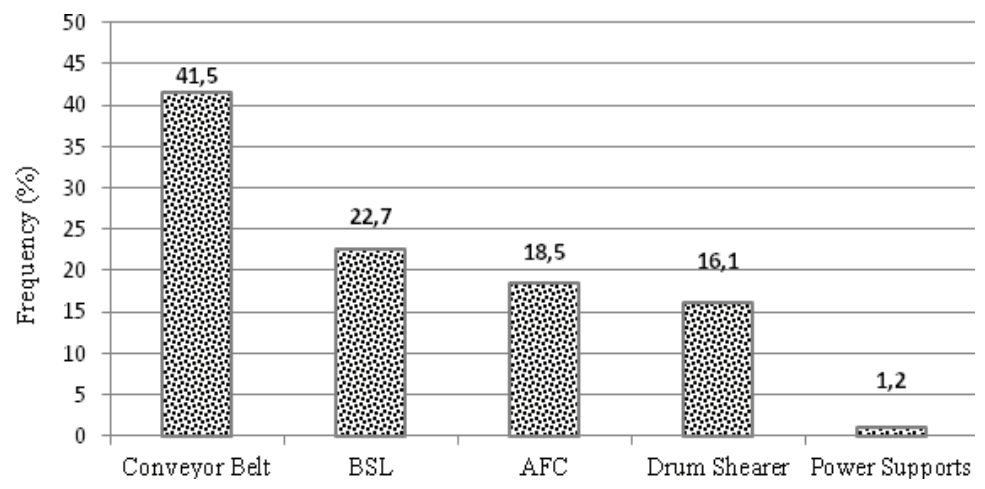

Fig. 2. Pareto analysis of production process subsystems in case study mine

As shown in the Fig. 2, the conveyor belt has the highest failure frequency, with 41.5 percent of all failures. The conveyor belt is the largest production subsystem; it is 
very difficult to monitor and manage properly. Power supports have the lowest failure frequency, with 1.2 percent of the failures and production stoppages.

After data collection, to validate the iid nature of the time between failures (TBF) data, starts by applying the military handbook analytic trend test to the data (Table 2). The assumption the failure data of subsystems do not follow any trend was rejected for all machines except the drum shearer and powered supports.

Next, the reliability of the AFC, BSL and conveyor belt was analyzed using the nonhomogeneous Poisson process. In this study, we used the power law process (PLP) for the reliability modeling of these three machines. The failure data of the drum shearer and powered supports follow three-parameter Weibull and Gamma distributions, respectively.

Table 2. Results of analytic testing of subsystems of longwall production chain

\begin{tabular}{|c|c|c|c|c|c|c|}
\hline $\begin{array}{c}\text { Modeling } \\
\text { method }\end{array}$ & $\begin{array}{c}\text { Null } \\
\text { hypothesis }\end{array}$ & $\begin{array}{c}97.5 \% \text { level } \\
\text { of significance }\end{array}$ & $\begin{array}{c}2.5 \% \text { level } \\
\text { of significance }\end{array}$ & $\begin{array}{c}\text { Calculated } \\
\text { statistic } U\end{array}$ & $\begin{array}{c}\text { Degree } \\
\text { of freedom }\end{array}$ & Equipment \\
\hline PLP & Rejected & 295.68 & 208.09 & 195.4 & 250 & AFC \\
\hline PLP & Rejected & 358.52 & 261.28 & 457.1 & 308 & BSL \\
\hline PLP & Rejected & 631.70 & 500.09 & 838.4 & 564 & Conveyor Belt \\
\hline RP & Not rejected & 253.44 & 178.16 & 184.95 & 218 & Drum Shearer \\
\hline RP & Not rejected & 21.02 & 5.22 & 6.98 & 12 & Power supports \\
\hline
\end{tabular}

\subsection{RELIABILITY ANALYSIS}

After the iid tests, we do the investigation of the best-fitted failure density functions on the available data for each machine by using Easyfit software. The Kolmogorov -Smirnov (K-S) test was used to select the best distribution among the top choices. Table 3 illustrates the results of data analysis and best-fit distributions.

Table 3. Results of data analysis and distribution parameters

\begin{tabular}{|l|l|l|}
\hline \multicolumn{1}{|c|}{ Parameters } & \multicolumn{1}{|c|}{ Best-fitted distribution } & \multicolumn{1}{|c|}{ Equipment } \\
\hline $\begin{array}{l}\alpha=1.29 \\
\beta=59.9\end{array}$ & Power law process & AFC \\
\hline $\begin{array}{l}\alpha=0.68 \\
\beta=2.64\end{array}$ & Power law process & BSL \\
\hline$\alpha=0.67$ & Power law process & Conveyor belt \\
$\beta=0.6$ & Weibull & \\
\hline$\alpha=20.1$ & & Drum Shearer \\
$\beta=0.75$ & Gamma & \\
$\gamma=0.75$ & Powered supports \\
\hline$\alpha=0.78$ & & \\
$\beta=115.3$ & &
\end{tabular}


As seen in Fig. 3, the reliability of the AFC, BSL, conveyor belt, drum shearer and powered supports reaches zero after about $220,30,8,180,520$ hours of operation, respectively. It takes about $45,1.5,0.5,13$ and 55 hours to reach 50 percent reliability for the AFC, BSL, conveyor belt, drum shearer and powered supports, respectively. Among the subsystems of the production process, powered supports are the most reliable. In contrast, the conveyor belt is the most critical subsystem; its reliability reaches zero before any other subsystem. A severe descending slope in the BSL and the conveyor belt shows they are not as reliable as required, especially the latter. This low level of reliability has two possible causes, inadequate maintenance scheduling or overloaded equipment.

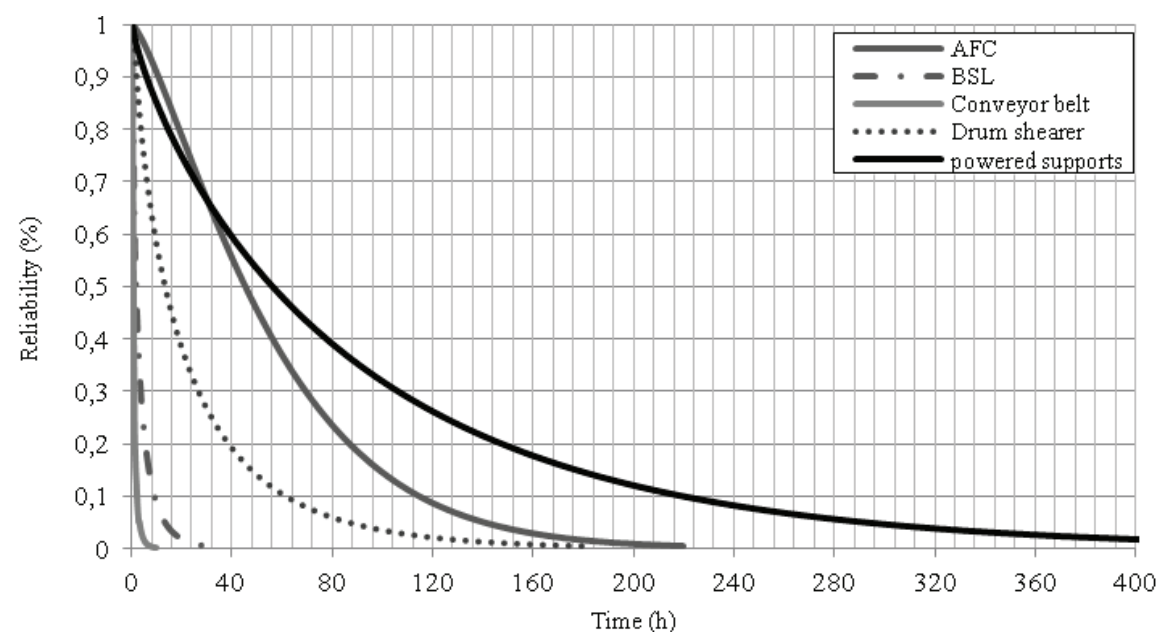

Fig. 3. Reliability plots of production subsystems

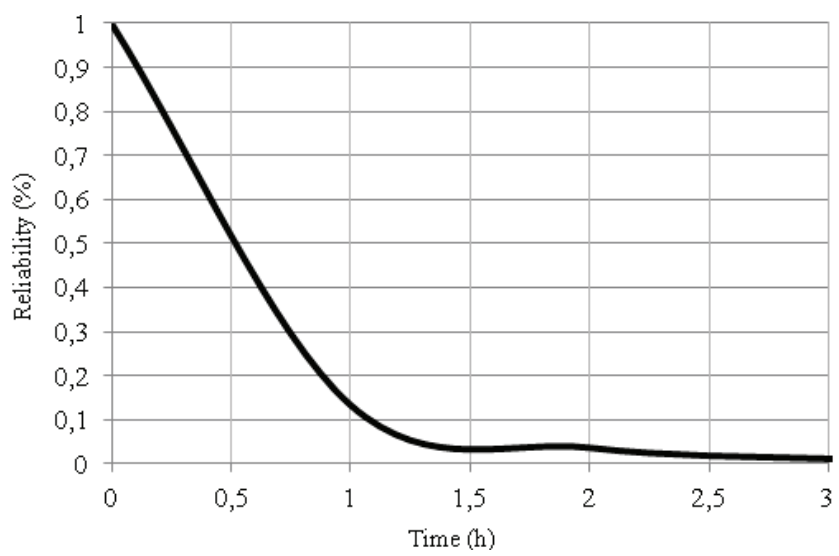

Fig. 4. Production reliability plot of the long-wall face under study 
Figure 3 illustrates the reliability plots and the series configuration, calculated production reliability. As shown in Fig. 4, production reliability is reduced to zero in about three hours, with a 50 percent chance the production process will not fail for the first 30 minutes of operation. This operation needs serious attention and has a high potential for stoppage, representing the most critical threat for production continuity.

\subsection{MAINTENANCE SCHEDULING}

In long-wall mining, the stoppage of one component results in the shutdown of the whole operation, causing numerous operational and economic problems for the mine and processing factory. Based on our cost analysis in the case study associated with mines, the value of the produced coal per minute is $146.85 \$ / \mathrm{min}$, on average, which means any breakdowns in production can lead to a $146.85 \$ / \mathrm{min}$ loss for the mine, making it crucial to reduce failures. We ensure a smooth operation by keeping the whole system and its various components at a high level of reliability and availability.

Knowing these facts, reliability-based preventive maintenance seems a suitable policy. In this approach, the preventive maintenance intervals, estimated by the reliability model, are used to reach the desired levels of performance and operational reliability (Rahimdel 2016).

In this paper, the desired level of reliability of each subsystem was set at 80 percent to schedule the preventive maintenance. As shown in Figure 5, the reliability-based PM time intervals for the AFC, BSL, conveyor belt, drum shearer and powered supports are $18.7,0.3,0.06,3.5$ and 14.3 hours, respectively.

It is nearly impossible to stop the mining operation and complete the preventive maintenance tasks on each subsystem based on this schedule because of the short time intervals. The best way to fix this problem is to combine the maintenance tasks of the subsystems to develop an applicable maintenance schedule. To optimize the maintenance schedule, the tasks with similar intervals are slotted into a single interval which is acceptable for all relevant subsystems. By combining the tasks for the BSL and conveyor belt, preventive maintenance for both can be done every two hours, simultaneously. Similarly, we can do the preventive maintenance for the AFC, and powered supports every 16 hours, and for the drum shearer, every four hours. All equipment should be maintained every 16 hours.

The graphical view of the optimized mixed maintenance schedule is shown in Fig. 5 (Gharahasanlou 2017). As indicated in the Figure, the new maintenance schedule is manageable and applicable and can be efficiently used in the field. The preventive maintenance in such a schedule is similar to the concept of service; in dense maintenance schedules, the defined tasks must be performed as soon as possible to avoid large downtimes and unavailability. 


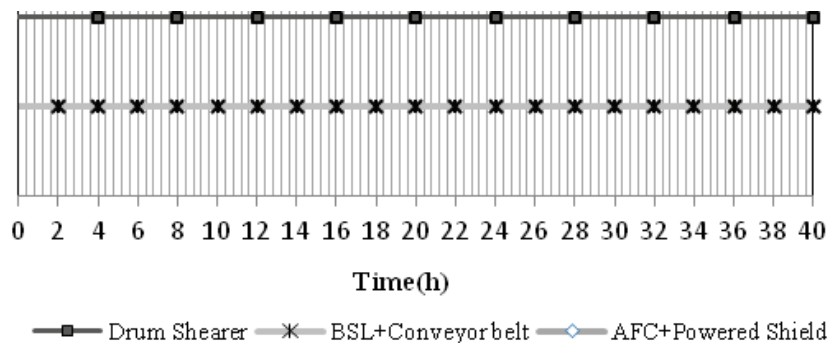

Fig. 5. Combined and improved preventive maintenance intervals

Finally, using the suggested schedule, the reliability of the production process can be improved. As shown in Fig. 6, after each preventive maintenance operation, the reliability of production process increases, directly related to the maintenance tasks and the number of the subsystems maintained.

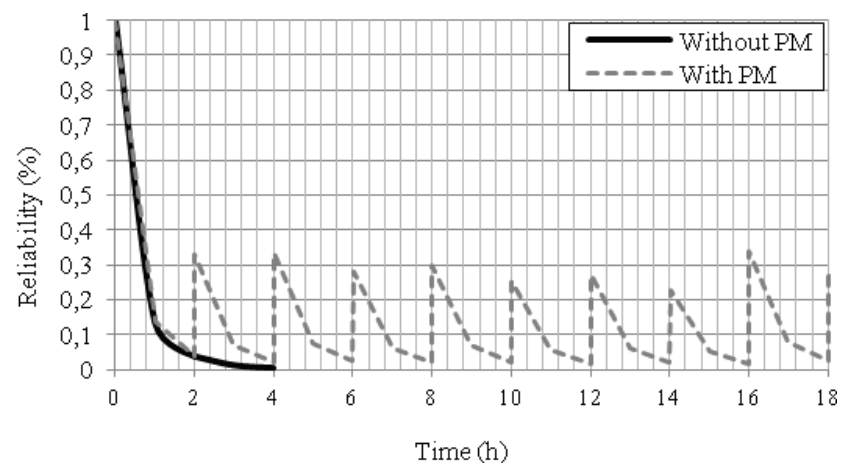

Fig. 6. Effects of preventive maintenance schedule on production reliability

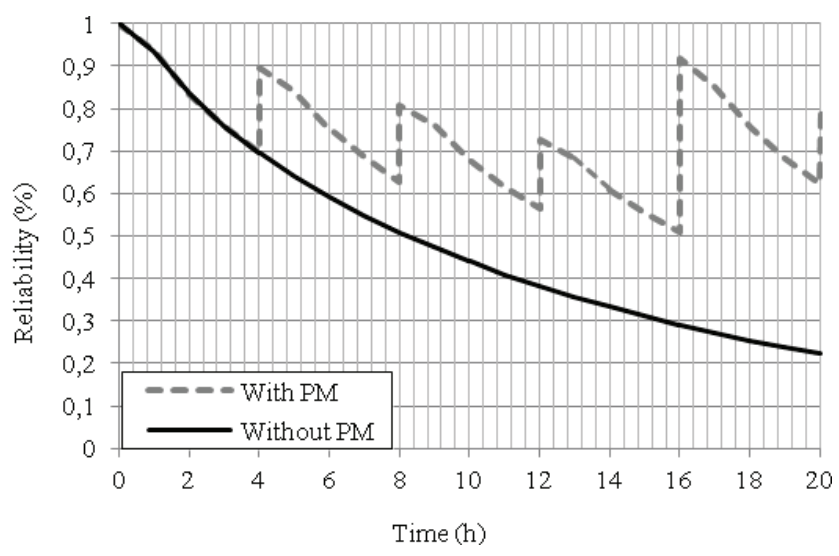

Fig. 7. Production reliability without considering conveyor belt and BSL 
Interestingly, the proposed maintenance plan does not improve production process reliability. Field studies and statistical analysis suggest the many failures in the conveyor belt and BSL are at fault. If we leave out these components, the production reliability plot looks like Fig. 7. As the figure indicates, the failures of the conveyor belt and BSL hurt production.

Back analysis shows the main problem in the conveyor belt and BSL is lying in their electrical units, making it extremely costly to reach 80 percent reliability for the entire production process and increasing the total cost of the extracted ore. We, therefore, offer the following five suggestions for improvement:

1. Since most of the failures occur in electrical units of the machines (Morshedlou et al. 2014b), paying more maintenance attention to them is highly recommended.

2. The conveyor belt of the main-gate is the most important factor in preventing the mine from achieving its production goals. Since it is costly to replace the whole machine, worn-out components like rollers, belts, and pulleys should be replaced as soon as possible because service and cleaning do not improve their performance.

3. As amplifier failures attribute to a large number of AFC and BSL stops, so we should use high-quality amplifiers.

4. Since water systems failure cause the most of the drum shearer stops, we must maintain this system more carefully than other subsystems. To improve the water system performance, we recommend monitoring and surveying the congestion of the spry jets nozzles, water filters, input and output connectors and gaskets.

5. Disconnection of the hoses and pressure reduction are main reasons for failures in powered supports. For this reason, protection of the hoses is critical (Morshedlou et al. 2014a).

\subsection{THE EFFECTS OF PREVENTIVE MAINTENANCE ON PRODUCTION RISK}

Generally speaking, risk analysis separates what we know (the science) from what we don't know (the uncertainty); it focuses on uncertainties and how that might affect decision outcomes and, consequently, on the decision makers policies (Everitt and Melnick 2008; Yoe 2012).

In this paper, we use mean production per shift (MPS) in four scenarios to evaluate the effects of the proposed maintenance schedule on production risk. The possible system statuses are the following:

1st scenario: the planned production; MPS should be 1370 tons to achieve the production goal of 1.5 million tons of coal per year.

2nd scenario: the current situation (i.e., current failures) without employing the maintenance schedule. For calculating the average production of the long-wall system, at first, we record the production level (tones) in 
shifts in which only failure of one car occurred. Then, we calculate the mean production per shift (MPS) for each machine by dividing the sum of productions to the number of their shifts. We achieve the average production of the long-wall system, at the time of failure, from the average of machines' MPS. Given that the downtime created in the production system varies by the machines, weighting the MPS of each machine is urgent. In order to obtain the average production of the long-wall system, the following equation was used:

$$
\text { Average Production per shift }=\frac{\sum_{i=1}^{5}\left(W_{i} * M P S_{i}\right)}{\sum_{i=1}^{5} W_{i}},
$$

which $W$ is weight of the MPS of a machine. According to the above equation, the average production for the system when failures occur is 452 tons.

Table 4. Production rate per shift based on scenario 2

\begin{tabular}{|c|c|c|c|c|c|}
\hline Row & Equipment & $\begin{array}{c}\text { Average production } \\
\text { with failure in one piece } \\
\text { of equipment per shift } \\
\text { (ton) }\end{array}$ & $\begin{array}{c}\text { Number } \\
\text { of failures }\end{array}$ & $\begin{array}{c}\text { Total time } \\
\text { of failures } \\
\text { (hour) }\end{array}$ & Weight \\
\hline 1 & AFC & 594 & 47 & 153.2 & 22 \\
\hline 2 & Drum shearer & 498 & 72 & 142.667 & 16.5 \\
\hline 3 & BSL & 479 & 52 & 155.183 & 22.3 \\
\hline 4 & Shield & 463 & 4 & 6.95 & 1 \\
\hline 5 & Conveyor & 325 & 78 & 248.13 & 35.7 \\
\hline
\end{tabular}

3rd scenario: a shift without any failures in equipment; in this case, the MPS is 922 tons.

4th scenario: operation with considering the proposed maintenance schedule. This scenario assumes the efficiency of the maintenance procedure is 50 percent and the time of this procedure is negligible. Based on the maintenance scheduling, reliability will be 80 percent. According to this level of reliability and maintenance efficiency, the cutting time is calculated as 350 minutes per shift. Therefore, MPS is calculated as 758 tons.

Based on the Fig. 8, the MPS level of the third status is 48.6 percent lower than the first status. The comparison of the fourth status to the first and the third shows significant effects of the proposed maintenance schedule on production rate enhancement; more specifically, it is 2.3 times lower than the first and 1.22 times lower than the 
third. This comparison shows a big difference between the two real situations (the 2nd and 3rd) and indicates the importance of a proper maintenance schedule. When the proposed schedule is implemented, we see a 67.7 percent enhancement in the MPS level of the current situation (2nd status) of the mine, a considerable improvement.

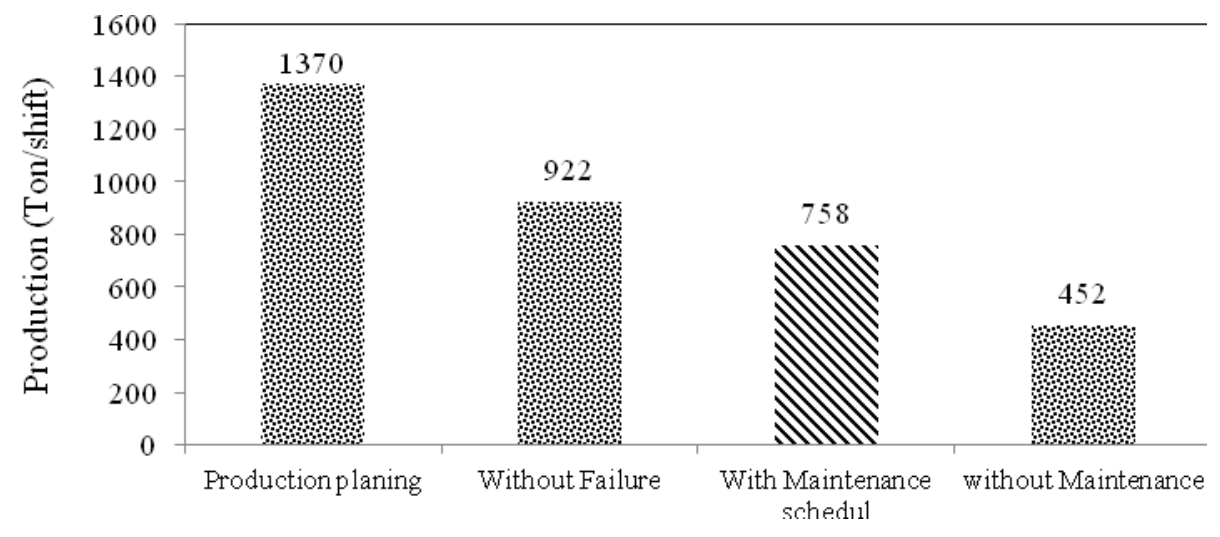

Fig. 8. Mean production per shifts in the various statuses of production process

\section{CONCLUSION}

Given the significant role of mechanization in the production rate and the importance of continuity of extraction in long-wall mines, it is essential to assess the reliability of the AFC, BSL, conveyor belt, drum shearer and powered supports to ensure the desired level of production. In this paper, we performed reliability and risk analysis on data from an Iranian long-wall mine and obtained the following results:

1. Pareto analysis shows the conveyor belt has the highest failure frequency among all the equipment, making it the critical subsystem of the production process. It is the major contributor to the reduction of the reliability of production.

2. Among the subsystems of the production process, powered supports seem the most reliable.

3. Production reliability is reduced to zero in a period of about three hours, indicating the need for serious attention. There is high potential for stoppages, the most critical threat for production continuity.

4. A maintenance task package developed for the production process in the case study mine suggests the preventive maintenance can be combined and done every two hours for the BSL and conveyor belt, every 16 hours for the AFC and powered supports, and every four hours for the drum shearer.

5. As the conveyor belt is the main factor in production stoppages, its worn-out components like rollers, belts and pulleys should be replaced as soon as possible. 
6. Hoses of the powered supports should be well protected.

7. High-quality amplifiers should be used, because most of AFC and BSL stops are related to them.

8. It is recommended to monitor the congestion of the spry jets nozzles, water filters, Input and output connectors and gaskets of the water system of the drum shearer.

9. When the proposed maintenance schedule is implemented, we expect to see an 67.7 percent increase in mean production per shift, a significant amount.

For increasing the reliability of production operation, we suggest that more skilled maintenance crew and spare parts management be applied. This value can be applied as the real utility of production process in Tabas coal mine and also generalized to the same mechanized long-wall mines with the same machines for studying performance analysis of long-wall equipment. Studying the effects of proposed PM schedule on the operational cost reductions and also the improvement of equipment reliability and availability should be included in future studies.

\section{ACKNOWLEDGMENT}

The authors are grateful to the employees and managers of National Iranian Steel Industries Company for their kind cooperation during data collection for this research. The financial support of Centre of Advanced Mining and Metallurgy (CAMM), Luleå University of Technology, is also acknowledged.

\section{REFERENCES}

BARABADY J., KUMAR U., 2007, Reliability analysis of mining equipment: a case study of a crushing plant at Jajarm bauxite mine in Iran, Reliability Engineering and Safety, 93, pp. 647-653.

BING-YUAN H., GANG S., LI-XUN K., 2009, Reliability emulation of production system on long-wall face, Journal of Coal Science and Engineering, 15(1), pp. 76-80.

CLARK R., DAWKINS G., KENNEDY R., GRAINGER A., LASAGHT A., 1991, Maintenance performance improvement - a structured approach. International Conference on Reliability, Production and Control in Coal Mines (Ed. H. Hargraves), 2-6 September, Wollongong, New South Wales, Australia.

CMTE Development, Ltd., 2002, CMTE studies pit automation and long-wall reliability, Mining Engineering, Vol. 54, No. 1 , p. 26.

CUTTS A., 1991, Improving the reliability of machine and systems used in the production processes, automation and control technologies. International Conference on Reliability, Production and Control in Coal Mines (Ed. H. Hargraves), 2-6 September, Wollongong, New South Wales, Australia.

EVERITT B.S., MELNICK E.L., 2008, Encyclopedia of quantitative risk analysis and assessment, Vol. 1, Wiley.

FAWCETT D.H., DUNCAN G.R., 1988, Long-wall face output-present state of the art- alternative future trends. 21st Century Higher Production Coal Mining Systems Symposium, 5-8 April, Wollongong, New South Wales, Australia.

FURULY S., BARABADY J., BARABADI A., 2014, Availability analysis of the main conveyor in the Svea Coal Mine in Norway, International Journal of Mining Science and Technology, Vol. 24, No. 5, pp. 587-591. 
GHARAHASANLOU A.N., ATAEI M., KHALOKAKAIE R., BARABADI A., EINIAN V., 2017, Risk based maintenance strategy: a quantitative approach based on time-to-failure model, International Journal of System Assurance Engineering and Management, 8(3), pp. 602-611.

GUPTA S., BHATTACHARYA J., 2007, Reliability Analysis of a Conveyor System using Hybrid Data, Quality and Reliability Engineering International, 23, pp. 867-882.

GUPTA S., RAMKRISHNA N., BHATTACHARYA J., 2006, Replacement and maintenance analysis of long-wall shearer using fault tree technique, Mining Technology, 115(2), pp. 49-58.

HENKEL E.H., 1991, Performance improvement of long-wall machinery. International Conference on Reliability, Production and Control in Coal Mines (Ed. H. Hargraves), 2-6 September, Wollongong, New South Wales, Australia.

HOSEINIE S.H., 2011, Modeling and simulation of drum shearer's reliability at mechanized long-wall mines - case study: Tabas coal mine, PhD Thesis, Shahroud University of Technology, Shahroud.

HOSEINIE S.H., AHMADI A., GHODRATI B., KUMAR U., 2013, Reliability-Centered Maintenance Program Development for the Spray Jets of Coal Shearer Machine, International Journal of Reliability, Quality and Safety Engineering, Vol. 20, No. 3, pp. 1-24.

HOSEINIE S.H., ATAIE M., KHALOOKAKAEI R., KUMAR U., GHODRATI B., 2012, Reliability analysis of drum shearer machine at mechanized long-wall mines, Journal of Quality in Maintenance Engineering, 18(1), pp. 98-119.

KUMAR U., 1990, Reliability analysis of load-haul-dump machines, PhD thesis, Lulea University of Technology, Lulea, Sweden.

Kumar U., Klefsjo B., 1992, Reliability analysis of hydraulic system of LHD machines using the power law process model, Reliability Engineering and System Safety, 35(3), pp. 217-224.

MANDAL S.K., BANIK P.K., 1996, Evaluation of Reliability Index of Long-wall Equipment Systems, Mining Technology, Vol. 78(897), pp. 138-140.

MIL-STD-2173, 1986, Reliability Centered Maintenance, Department of Defense, Washington, DC, USA.

MORSHEDLOU A., DEHGHANI H., HOSEINIE S.H., 2014a, Reliability-based maintenance scheduling of powered supports in Tabas mechanized coal mine, Journal of Mining and Environment (JME), 5(2), pp. 113-120.

MORSHEDLOU A., DEHGHANI H., HOSEINIE S.H., 2014b, Comparison between reliability of electrical and mechanical units of long-wall machineries in Tabas coal mine. 9th Iranian Conference of Maintenance, 20-21 May, Tehran, Iran.

MRIG G.C., 1991, Reliability of machines and systems used in production process in mines - a case study of South Eastern Coalfields Limited. International Conference on Reliability, Production and Control in Coal Mines (Ed. H. Hargraves), 2-6 September, Wollongong, New South Wales, Australia.

RAHIMDEL M.J., HOSEINIE S.H., GHODRATI B., 2016, RAM analysis of rotary drilling machines, Journal of Mining Science, 18, pp. 77-89.

RAUSAND M., HØYLAND A., 2004, System Reliability Theory: Models, Statistical Methods and Applications, John Wiley, Hoboken, USA.

SHEN G., JIANG G., 1991, Coal mine modernization and production reliability in China. International Conference on Reliability, Production and Control in Coal Mines (Ed. H. Hargraves), 2-6 September, Wollongong, New South Wales, Australia.

VELZEBOER M.D., 1988, Implication of high productivity long-wall systems. 21st Century Higher Production Coal Mining Systems Symposium, 5-8 April, Wollongong, New South Wales, Australia.

YOE C., 2012, Principles of risk analysis; Decision making under uncertainty, CRC Press, Taylor \& Francis Group. 